\title{
ResearchOnline@JCU
}

This is the author-created version of the following work:

Chew, Peter K.H., and Yap, Brian L.M. (2021) Mortality salience in an offline and online setting. Death Studies, . (In Press)

Access to this file is available from:

https://researchonline.jcu.edu.au/68202/

Published Version: (C) 2021 Taylor \& Francis Group, LLC. Accepted Version may be posted in an Institutional Repository under a CC BY-NC-ND after a 12 month embargo.

Please refer to the original source for the final version of this work: 


\section{Mortality salience in an offline and online setting}

Peter K. H. Chew ${ }^{\mathrm{a},{ }^{*}}$ \& Brian L. M. Yap ${ }^{\mathrm{a}}$

a James Cook University, 149 Sims Drive, Singapore 387380

*Corresponding author. Tel.: +65 6709 3747; Fax: +65 6709 3889; e-mail:

$$
\text { peter.chew@jcu.edu.au }
$$




\begin{abstract}
The current study aims to examine the effects of mortality salience effects on worldview defense in an offline and online setting. Participants were 146 (66 offline and 80 online) Singaporeans. Participants were randomly assigned to either the mortality salience condition or the control condition and after a delay completed a Worldview Defense Assessment. No significant mortality salience effects on worldview defense occurred in either setting. The results might be explained by the Asian sample, Singapore's culture of tolerance, and data collection during the Coronavirus Disease 2019 (COVID-19) pandemic. Future research directions include examining the effects of COVID-19 in activating worldview defense.
\end{abstract} Keywords: terror management, mortality salience, worldview defense, Singapore 


\section{Mortality salience in an offline and online setting}

Terror management theory posits that mortality salience motivates individuals to defend their cultural worldview (Greenberg et al., 1986). This prediction has since been supported by more than 250 experiments (Burke et al., 2010). However, most studies have been done offline in Western samples, a limitation on the generalizability of terror management theory. The current study aims to examine mortality salience effects offline in a laboratory and online via Qualtrics using Singaporean samples.

All living things are driven by an instinct to survive. However, unlike other living things, human beings possess the necessary cognitive capacities to recognize that we will eventually die. According to terror management theory, awareness of the inevitability of death in an organism with a preference for life results in overwhelming anxiety (terror) (Greenberg et al., 1986). The organism manages this anxiety by a combination of proximal and distal defenses (Pyszczynski et al., 1999). When death-related thoughts are conscious (e.g., immediately after being reminded of death), we engage in proximal pseudo-rational defenses like denying one's vulnerability to suppress those thoughts. Subsequently, when death-related thoughts are unconscious but accessible (e.g., after a delay), we engage in distal experiential defenses like defending our cultural worldview and bolstering self-esteem. Together, these defenses enable us to live with equanimity.

We invented culture partly to deal with the problem of death (Solomon et al., 1991). A cultural worldview provides (a) meaning to life, (b) a set of standards to strive for, and (c) the promise of literal (afterlife) or symbolic immortality (being remembered by the next generation) for those who meet those standards. Further, meeting those standards enable us to obtain self-esteem. However, two consequences arise from culture being a human invention. First, cultural worldviews are fragile and require validation from similar others. Second, different groups of people will invent and adhere to different cultural worldviews. Because 
exposure to different worldviews raises the possibility that one's worldview is incorrect, much of human behavior is driven by the need to defend one's cultural worldview.

The mortality salience hypothesis is often used to test the predictions of terror management theory (Burke et al., 2010). The hypothesis states that if cultural worldviews and self-esteem are buffers against death-related thoughts, then reminders of death (i.e., mortality salience) should motivate us to defend our cultural worldview or to bolster self-esteem. For example, participants reminded of death showed higher worldview defense in the form of more positive and negative attitudes towards pro-USA and anti-USA essays, respectively (Greenberg et al., 1992, 1994), and were more aggressive towards individuals who threaten their worldview (McGregor et al., 1998). Furthermore, participants reminded of death were more likely to engage in risky behaviors such as reckless driving (Taubman Ben-Ari et al., 1999) and sun-tanning (Routledge et al., 2004), if these behaviors were relevant to participants' self-esteem. Overall, a recent meta-analysis of more than 250 experiments supported the mortality salience hypothesis (Burke et al., 2010).

Nevertheless, a recent large-scale replication study in the U.S. failed to support the mortality salience hypothesis (Klein et al., 2019). The study, involving 21 laboratories and a total of 2220 participants, sought to replicate the findings of a classic mortality salience study (Greenberg et al., 1994). A meta-analysis of the results across the 21 laboratories failed to replicate the original effect of mortality salience on worldview defense. In response, a team lead by one of the original authors of terror management theory reanalyzed the data by only including studies with at least 40 participants per condition (Chatard et al., 2020). The reanalysis successfully replicated the results of the classic study, suggesting that inclusion of studies with small samples might have contributed to the failed replication. However, the argument is weakened by the fact that the classic study found significant mortality salience effects with only 11 to 12 participants per condition (Greenberg et al., 1994). Issues of 
replicability aside, there are at least two limitations associated with the terror management theory literature.

First, most studies have been done offline in a laboratory (Burke et al., 2010), although some studies have been conducted online (e.g., Kugler \& Cooper, 2010; Strachman \& Schimel, 2006; Xu \& Brucks, 2011; Zaleskiewicz et al., 2013). In addition to the advantage of recruiting larger and more diverse samples from online studies, there are disadvantages associated with offline laboratory studies. Because distal defenses are experiential in nature (Pyszczynski et al., 1999), mortality salience effects are only found among participants in an experiential, but not rational, mode of thinking (Simon et al., 1997). To elicit experiential thinking, experimenters should dress informally, behave casually, and collect data in less formal settings. Such procedures are challenging to implement and there could be considerable variability in context across studies (Klein et al., 2019).

Furthermore, the aforementioned meta-analysis (Burke et al., 2010) has been reanalyzed to examine effect sizes across different teams of researchers (Yen \& Cheng, 2013). The results showed that studies affiliated with the original authors of terror management theory had significantly larger effect sizes than studies conducted by other researchers. This discrepancy could be due to differences in experimenters' expertise, publication bias, and researchers' degrees of freedom (i.e., flexibility in data collection and analysis). Conducting studies online addresses some of these limitations. Logically speaking, we should expect larger effect sizes in online studies because participants are in their own environment as opposed to a relatively formal laboratory and should be in an experiential mode of thinking. More important, online studies do not require the physical presence of an experimenter, reducing the need for experimenters' expertise and the potential for bias.

Second, although some studies have been conducted using non-Western samples (e.g., Kashima et al., 2004; Ma-Kellams \& Blascovich, 2011, 2012; Yen \& Cheng, 2010), most 
studies have been done using Western samples (Burke et al., 2010). In fact, most studies recruited psychology undergraduates from Western, educated, industrialized, rich, and democratic societies as participants (WEIRD samples; Henrich et al., 2010). Current evidence suggests that mortality salience effects do not generalize to non-Western samples. For example, because Chinese people view death differently from Westerners, they are more likely to respond to death-related thoughts by resigning to fate rather than engaging in worldview defense. Indeed, a study among Chinese people in Taiwan found that mortality salience did not have a significant effect on worldview defense (Yen \& Cheng, 2010). Subsequently, the authors conducted a meta-analysis of 24 mortality salience experiments in Taiwan, Hong Kong, and Japan, and found similar results. Clearly, there is a pressing need to examine mortality salience effects in other non-Western samples to identify the boundaries of terror management theory.

The current study aims to examine mortality salience effects offline in a laboratory and online via Qualtrics using Singaporean samples. There are two methods to examine the validity of online research (Krantz \& Dalal, 2000). Researchers could either compare the results between offline and online studies (e.g., Krantz et al., 1997) or examine if the results are consistent with the predictions made by the theory (e.g., Allen, 1999). Both methods were used in the current study. Specifically, we hypothesized that participants in the mortality salience condition would have higher worldview defense than their counterparts in the control condition in both the offline and online setting.

$$
\text { Method }
$$

\section{Participants}

Participants were a sample of 180 Singaporeans or permanent residents who have lived in Singapore for at least 10 years; we removed 34 participants because they were aware of the aims of the study, did not provide informed consent, or did not provide a response for 
the Mortality Attitudes Personality Survey. The final sample consisted of 146 participants ( $54 \%$ or 79 women) with an age range of 18 to 52 years $(M=24.64, S D=4.05)$. Given alpha $=.05$, power $=.80$, and a moderate effect size, $\mathrm{G}^{*}$ Power analysis recommends a minimum sample size of 116 participants (Faul et al., 2009). Within the final sample, 66 participants ( $53 \%$ or 35 women) completed the study offline. Their age ranges from 18 to 39 years $(M=$ $24.21, S D=3.33)$. The remaining 80 participants ( $55 \%$ or 44 women) completed the study online. Their age ranges from 18 to 52 years $(M=25.0, S D=4.55)$.

\section{Instruments}

The Mortality Attitudes Personality Survey is a two-item task designed to manipulate mortality salience (Rosenblatt et al., 1989). The task was presented to participants as a 'Projective Life Attitudes Assessment', an innovative method for the assessment of an individual's personality via content analysis. The two items are: (a) please briefly describe the emotions that the thought of [your own death (mortality salience) OR taking an examination (control)] arouses in you and (b) jot down, as specifically as you can, what you think will happen to you as you [physically die and once you are physically dead (mortality salience) OR take an examination paper and once you complete that paper (control)]. In a recent meta-analysis, $79.8 \%$ of the 277 studies used the Mortality Attitudes Personality Survey for mortality salience manipulation (Burke et al., 2010). We assessed the time taken to complete this instrument discreetly using a stopwatch for the offline participants and the timer feature on Qualtrics for the online participants. In addition, we recorded the number of words used for the two items.

The Positive and Negative Affect Schedule is a 20-item instrument designed to assess Positive Affect (e.g., Attentive) and Negative Affect (e.g., Distressed) (Watson et al., 1988). Participants were asked to report their feelings and emotions in the present moment. Responses are on a 5-point Likert scale that ranges from $1=$ Very Slightly or Not at All to $5=$ 
Extremely. Appropriate item scores are summed for each factor, with higher scores indicating higher levels of positive or negative affect. Scores on the instrument range from 10 to 50 for each factor. The two-factor structure of the instrument has been supported by exploratory factor analysis (Watson et al., 1988). In addition, among 660 psychology undergraduates, Positive and Negative Affect had acceptable internal consistencies of .89 and .85, respectively (Watson et al., 1988). In the current study, Positive and Negative Affect had acceptable internal consistencies of .88 and .92 , respectively.

The Worldview Defense Assessment consists of two essays ostensibly written by two foreigners (Greenberg et al., 1992). The two essays were adapted for use among Singaporeans in the current study. Specifically, the pro-Singapore essay praises Singapore and focuses on meritocracy, social mobility, and opportunities. The anti-Singapore essay criticizes Singapore and focuses on elitism, exploitation of foreigners, and laziness of Singaporeans. The order of the essays was randomized to control for order effects. After each essay, participants were asked to evaluate (a) the author of the essay on three items (e.g., How much do you like this person?, How intelligent did you think this person was?, and How knowledgeable did you think this person was?) and (b) the content of the essay on two items (e.g., How much did you agree with this person's opinion of Singapore? and From your perspective, how true do you think this person's opinion of Singapore is?). Responses are on a 9-point Likert scale that ranges from $1=$ Not at All to $9=$ Totally. Appropriate item scores are summed for the author and the content, with higher scores indicating a more positive evaluation. Finally, two worldview defense scores (author and content) are computed by subtracting the evaluation scores of the anti-Singapore essay from scores of the proSingapore essay, with higher scores indicating higher levels of worldview defense. In the current study, the three items for the author of the essay had acceptable internal consistencies 
of .79 (pro-Singapore) and .85 (anti-Singapore). The two items for the content of the essay had acceptable internal consistencies of .90 (pro-Singapore) and .93 (anti-Singapore).

\section{Procedure}

Participants were recruited via convenience and snowball sampling from the research participation program of the university. Eligible participants received course credits for participation. Participants completed the study either offline in a laboratory or online via Qualtrics. To hide the true nature of the study, participants were told that the study aims to examine how personality traits predict reactions to foreigners' impressions of Singapore. To elicit experiential thinking, the experimenter in the offline setting dressed informally and behaved casually. First, participants completed two filler instruments to support the cover story of the study. Second, participants were randomly assigned to either the mortality salience condition or the control condition. Third, participants completed the Positive and Negative Affect Schedule (Watson et al., 1988), which introduced a delay between the mortality salience manipulation and the assessment of the dependent variables. Fourth, participants completed the Worldview Defense Assessment (Greenberg et al., 1992) and a demographic form. At the end of the experiment, participants were probed for suspicion (What do you think are the aims of the study?) and debriefed about the true nature of the study. The study was conducted in English and data collection took place from December 2019 to January 2020. This procedure was approved by the university's Human Research Ethics Committee (Approval number: H7920).

\section{Results}

A series of independent samples $t$-tests and a chi-square test were conducted to examine differences between offline $(n=66)$ and online participants $(n=80)$. In terms of demographics, there were no significant differences in age between the offline $(M=24.21$, $S D=3.33)$ and online participants $(M=25.0, S D=4.55)$. There were also no significant 
differences in sex distribution between the two groups (53\% vs. 55\% women). Overall, offline participants took a longer amount of time $(M=245.02$ seconds, $S D=147.49$, vs. $M=$ 178.69 seconds, $S D=213.45), t(144)=-2.14, p=.03$, Cohen's $d=0.36$ and wrote more words for Item $1(M=25.03, S D=22.92$, vs. $M=8.75, S D=10.00), t(144)=-5.73, p<.001$, Cohen's $d=0.92$ and Item $2(M=30.98, S D=22.69$, vs. $M=18.65, S D=15.19), t(144)=$ 3.92, $p<.001$, Cohen's $d=0.64$ of the Mortality Attitudes Personality Survey than online participants. Furthermore, offline participants had less positive affect $(M=26.53, S D=7.34$, vs. $M=30.51, S D=6.61), t(144)=3.45, p<.001$, Cohen's $d=0.57$ and less negative affect $(M=14.83, S D=5.44$, vs. $M=24.55, S D=7.49), t(144)=8.80, p<.001$, Cohen's $d=1.48$ than online participants.

A series of independent samples $t$-tests were conducted to examine differences between participants in the mortality salience condition $(n=72)$ and control condition $(n=$ 74). There were no significant differences in positive affect $(M=29.18, S D=6.76$ vs. $M=$ $28.26, S D=7.63)$ and negative affect $(M=21.19, S D=8.73$ vs. $M=19.15, S D=7.59)$ between the two conditions.

A 2(Condition: Mortality Salience vs. Control) x 2(Setting: Offline vs. Online) MANOVA $^{1}$ was conducted with the two worldview defense scores (author and content) as the dependent variables. The descriptives are presented in Table 1. There was no significant interaction effect between condition and setting. There were also no significant main effects for condition and setting.

Bayesian analyses were conducted to examine the nonsignificant results (Wagenmakers, Love, et al., 2018; Wagenmakers, Marsman, et al., 2018). Specifically, two Bayesian ANOVAs were conducted to examine the effects of condition and setting on

\footnotetext{
${ }^{1}$ Given the differences between the offline and online participants, a 2(Condition: Mortality Salience vs. Control) x 2(Setting: Offline vs. Online) MANCOVA was conducted with time spent, number of words written, positive affect, and negative affect as covariates, and the two worldview defense scores (author and content) as the dependent variables. There was no significant interaction effect between condition and setting. There were also no significant main effects for condition and setting.
} 
worldview defense of the author and content. For worldview defense of the author, the Bayes factor is $7.85,7.95$, and 32.81 in favor of the null hypothesis for the main effects of condition and setting, and the interaction effect between condition and setting. For worldview defense of the content, the Bayes factor is $7.78,6.47$, and 31.67 in favor of the null hypothesis for the main effects of condition and setting, and the interaction effect between condition and setting. According to the classification scheme for Bayes factors, the results provided moderate to strong evidence for the null hypothesis (Lee \& Wagenmakers, 2013).

\section{Discussion}

The results of this study did not provide support for the hypothesis that participants in the mortality salience condition would have higher worldview defense than their counterparts in the control condition in both the offline and online setting. Despite differences between the two settings (e.g., time spent on and number of words written for the Mortality Attitudes Personality Survey), the results were both nonsignificant and will be discussed together in this section. The nonsignificant results was consistent with previous studies using nonWestern samples (Yen \& Cheng, 2010) but inconsistent with studies using Western samples (Burke et al., 2010). The nonsignificant results might be explained by the use of an Asian sample, Singapore's culture of tolerance, and data collection during the Coronavirus Disease 2019 (COVID-19) pandemic.

First, the study was conducted using an Asian sample. Because Chinese view death differently from Westerners, Chinese in Taiwan responded to death-related thoughts by resigning to fate rather than engaging in worldview defense (Yen \& Cheng, 2010). While ethnicity data was not collected in the current study, the latest population census indicated that $74.1 \%$ of Singaporeans are Chinese (Singapore Department of Statistics, 2010) and they might have responded in a similar manner as Chinese in Taiwan. However, there is some evidence that Chinese Singaporeans are different from Chinese from other regions (Cheung et 
al., 2006). Furthermore, Singapore consists of other races like Malays (13.4\%) and Indians (9.2\%), and they might have different views of death from Chinese. To our knowledge, no research has been conducted to examine how Singaporeans and the major ethnic groups in Singapore view death. Future research could address this gap and potentially explain the results of the current study.

Second, Singapore actively promotes a culture of tolerance given that it is a multiracial and multi-religious country (Pew Research Center, 2014; Singapore Department of Statistics, 2010). Although there are some evidence of outgroup derogation (Chew, 2018; Chew et al., 2019), tensions and conflicts between the major ethnic and religious groups are relatively low compared to other countries due to the culture of tolerance. This culture is enforced by laws prohibiting outgroup derogation (Penal Code, 1871; Sedition Act, 1948) and supported by a government that endorses diversity (Roets et al., 2015). Because of this culture, participants in the current study might be reluctant to provide a negative evaluation of the anti-Singapore essay that was ostensibly written by a foreigner. Indeed, one study found that participants who are tolerant (either dispositional or primed) do not show the usual worldview defense when reminded of mortality (Greenberg et al., 1992).

Lastly, data was collected during the COVID-19 pandemic. Data for the current study was collected from December 2019 to January 2020. Although the World Health Organization only declared an international emergency on $31^{\text {st }}$ January 2020 (The Straits Times, 2020), Singapore received news about COVID-19 since the start of January and reported its first COVID-19 case on 23 ${ }^{\text {rd }}$ January 2020 (Ministry of Health Singapore, 2020). A recent paper argued that given COVID-19's contagiousness and severity, it might have acted as a form of mortality salience, resulting in an increase in death-related thoughts (Courtney et al., 2020). In the current study, participants in the control condition might have 
engaged in worldview defense to buffer against those thoughts. Consequently, no significant differences in worldview defense were found between the two conditions.

Although there are explanations for the nonsignificant results in the current study, researchers need to consider the boundaries of terror management theory as negative evidence accumulates. Specifically, some predictions of the theory might not be replicable (Klein et al., 2019) or cross-culturally valid (Yen \& Cheng, 2010). The issue is exacerbated by the underestimation of negative evidence due to publication bias (Bakker et al., 2012; Ferguson \& Heene, 2012). While the meta-analysis that provided support for the mortality salience hypothesis found no evidence of publication bias (Burke et al., 2010), a reanalysis of the data found evidence of publication bias among the research team affiliated with the original authors of terror management theory (Yen \& Cheng, 2013). Furthermore, the metaanalysis that did not provide support for the mortality salience hypothesis consisted of $70.8 \%$ unpublished studies (Yen \& Cheng, 2010). Taken together, it is likely that the effects of mortality salience might be overestimated.

Limitations of the current study should be noted. First, the sample size of 146 did not meet the criterion of having at least 40 participants per condition (Chatard et al., 2020). However, significant effects of mortality salience on worldview defense have been found with as little as nine participants per condition (Greenberg et al., 1992). Furthermore, the current sample size exceeds the $G^{*}$ Power recommendation of at least 116 participants (Faul et al., 2009). Second, individual difference variables were not assessed in the current study. While previous studies have found mortality salience effects in the absence of moderators (e.g., Greenberg et al., 1994), potential moderators like tolerance should be considered if it is relevant to the cultural worldview of the participants. In the future, these limitations might be controlled by recruiting a larger sample and considering potential moderators. 
Future research directions might include assessing death-thought accessibility (Steinman \& Updegraff, 2015) instead of worldview defense. Because worldview defense could be moderated by tolerance (Greenberg et al., 1992), assessing death-thought accessibility enables researchers to directly examine the effects of mortality salience. Currently, it is unclear if the nonsignificant results are due to a lack of death-thought accessibility, or to an increase in death-thought accessibility but a lack of a worldview defense. Second, future research could examine the ability of COVID-19 to act as a form of mortality salience. For example, researchers could examine if reading about COVID-19 increases death-related thoughts and activates worldview defense. The findings could clarify the findings of the current study and other terror management theory research conducted during the COVID-19 pandemic.

In summary, the current study found that mortality salience did not result in an increase in worldview defense in both the offline and online setting. While there are alternative explanations for the nonsignificant results, the presence of negative evidence suggests that some predictions of terror management theory might not be replicable or crossculturally valid. Clearly, more replication research needs to be conducted using non-Western samples to delineate the boundaries of the theory. 


\section{References}

Allen, B. P. (1999). Shadows as sources of cues for distance of shadow-casting objects. Perceptual and Motor Skills, 89(2), 571-584. https://doi.org/10.2466/pms.1999.89.2.571

Bakker, M., van Dijk, A., \& Wicherts, J. M. (2012). The rules of the game called psychological science. Perspectives on Psychological Science, 7(6), 543-554. https://doi.org/10.1177/1745691612459060

Burke, B. L., Martens, A., \& Faucher, E. H. (2010). Two decades of terror management theory: A meta-analysis of mortality salience research. Personality and Social Psychology Review, 14(2), 155-195. https://doi.org/10.1177/1088868309352321

Chatard, A., Hirschberger, G., \& Pyszczynski, T. (2020). A word of caution about many labs 4: If you fail to follow your preregistered plan, you may fail to find a real effect. PsyArXiv. https://doi.org/10.31234/osf.io/ejubn

Cheung, S. F., Cheung, F. M., Howard, R., \& Lim, Y.-H. (2006). Personality across the ethnic divide in Singapore: Are "Chinese Traits" uniquely Chinese? Personality and Individual Differences, 41(3), 467-477. https://doi.org/10.1016/j.paid.2005.12.023

Chew, P. K. H. (2018). Racism in Singapore: A review and recommendations for future research. Journal of Pacific Rim Psychology, 12, 1-9. https://doi.org/10.1017/prp.2018.3

Chew, P. K. H., Young, J. L., \& Tan, G. P. K. (2019). Racism and the Pinkerton syndrome in Singapore: Effects of race on hiring decisions. Journal of Pacific Rim Psychology, 13, 1-7. https://doi.org/10.1017/prp.2019.9

Courtney, E. P., Goldenberg, J. L., \& Boyd, P. (2020). The contagion of mortality: A terror management health model for pandemics. British Journal of Social Psychology, 59(3), 607-617. https://doi.org/10.1111/bjso.12392 
Faul, F., Erdfelder, E., Buchner, A., \& Lang, A.-G. (2009). Statistical power analyses using $\mathrm{G}^{*}$ Power 3.1: Tests for correlation and regression analyses. Behavior Research Methods, 41(4), 1149-1160. https://doi.org/10.3758/BRM.41.4.1149

Ferguson, C. J., \& Heene, M. (2012). A vast graveyard of undead theories publication bias and psychological science's aversion to the null. Perspectives on Psychological Science, 7(6), 555-561. https://doi.org/10.1177/1745691612459059

Greenberg, J., Pyszczynski, T., \& Solomon, S. (1986). The causes and consequences of a need for self-esteem: A terror management theory. In R. F. Baumeister (Ed.), Public self and private self (pp. 189-212). Springer. https://doi.org/10.1007/978-1-46139564-5_10

Greenberg, J., Pyszczynski, T., Solomon, S., Simon, L., \& Breus, M. (1994). Role of consciousness and accessibility of death-related thoughts in mortality salience effects. Journal of Personality and Social Psychology, 67(4), 627-637. https://doi.org/10.1037/0022-3514.67.4.627

Greenberg, J., Simon, L., Pyszczynski, T., Solomon, S., \& Chatel, D. (1992). Terror management and tolerance: Does mortality salience always intensify negative reactions to others who threaten one's worldview? Journal of Personality and Social Psychology, 63(2), 212-220. http://dx.doi.org.elibrary.jcu.edu.au/10.1037/00223514.63.2.212

Henrich, J., Heine, S. J., \& Norenzayan, A. (2010). The weirdest people in the world? Behavioral and Brain Sciences, 33(2-3), 61-83.

Kashima, E. S., Halloran, M., Yuki, M., \& Kashima, Y. (2004). The effects of personal and collective mortality salience on individualism: Comparing Australians and Japanese with higher and lower self-esteem. Journal of Experimental Social Psychology, 40(3), 384-392. https://doi.org/10.1016/j.jesp.2003.07.007 
Klein, R. A., Cook, C. L., Ebersole, C. R., Vitiello, C., Nosek, B. A., Chartier, C. R., Christopherson, C. D., Clay, S., Collisson, B., Crawford, J., Cromar, R., Vidamuerte, D., Gardiner, G., Gosnell, C., Grahe, J., Hall, C., Joy-Gaba, J., Legg, A. M., Levitan, C., ... Ratliff, K. (2019). Many labs 4: Failure to replicate mortality salience effect with and without original author involvement. PsyArXiv. https://doi.org/10.31234/osf.io/vef2c

Krantz, J. H., Ballard, J., \& Scher, J. (1997). Comparing the results of laboratory and WorldWide Web samples on the determinants of female attractiveness. Behavior Research Methods, Instruments, \& Computers, 29(2), 264-269. https://doi.org/10.3758/BF03204824

Krantz, J. H., \& Dalal, R. (2000). Validity of Web-based psychological research. In M. H. Birnbaum (Ed.), Psychological Experiments on the Internet (pp. 35-60). Academic Press.

Kugler, M. B., \& Cooper, J. (2010). Still an American? Mortality salience and treatment of suspected terrorists. Journal of Applied Social Psychology, 40(12), 3130-3147. https://doi.org/10.1111/j.1559-1816.2010.00694.x

Lee, M. D., \& Wagenmakers, E. J. (2013). Bayesian cognitive modeling: A practical course. Cambridge University Press.

Ma-Kellams, C., \& Blascovich, J. (2011). Culturally divergent responses to mortality salience. Psychological Science, 22(8), 1019-1024. https://doi.org/10.1177/0956797611413935

Ma-Kellams, C., \& Blascovich, J. (2012). Enjoying life in the face of death: East-West differences in responses to mortality salience. Journal of Personality and Social Psychology, 103(5), 773-786. https://doi.org/10.1037/a0029366 
McGregor, H. A., Lieberman, J. D., Greenberg, J., Solomon, S., Arndt, J., Simon, L., \& Pyszczynski, T. (1998). Terror management and aggression: Evidence that mortality salience motivates aggression against worldview-threatening others. Journal of Personality and Social Psychology, 74(3), 590-605.

http://dx.doi.org.elibrary.jcu.edu.au/10.1037/0022-3514.74.3.590

Ministry of Health Singapore. (2020). MOH | Updates on COVID-19 (Coronavirus Disease 2019) Local Situation. https://www.moh.gov.sg/covid-19

Pew Research Center. (2014). Religious Diversity Around The World. Pew Research Center. https://www.pewforum.org/2014/04/04/global-religious-diversity/

Pyszczynski, T., Greenberg, J., \& Solomon, S. (1999). A dual-process model of defense against conscious and unconscious death-related thoughts: An extension of terror management theory. Psychological Review, 106(4), 835-845.

https://doi.org/10.1037/0033-295X.106.4.835

Roets, A., Au, E. W. M., \& Hiel, A. V. (2015). Can authoritarianism lead to greater liking of out-groups? The intriguing case of Singapore. Psychological Science, 26(12), 19721974. https://doi.org/10.1177/0956797615605271

Rosenblatt, A., Greenberg, J., Solomon, S., Lyon, D., \& Pyszcznski, T. (1989). Evidence for terror management theory: I. The effects of mortality salience on reactions to those who violate or uphold cultural values. Journal of Personality and Social Psychology, $57(4), 681$.

Routledge, C., Arndt, J., \& Goldenberg, J. L. (2004). A time to tan: Proximal and distal effects of mortality salience on sun exposure intentions. Personality and Social Psychology Bulletin, 30(10), 1347-1358. https://doi.org/10.1177/0146167204264056

Simon, L., Greenberg, J., Harmon-Jones, E., Solomon, S., Pyszczynski, T., Arndt, J., \& Abend, T. (1997). Terror management and cognitive-experiential self-theory: 
Evidence that terror management occurs in the experiential system. Journal of Personality and Social Psychology, 72(5), 1132-1146. https://doi.org/10.1037/00223514.72 .5 .1132

Singapore Department of Statistics. (2010). Census of population 2010 Statistical release 2: Households and housing.

Solomon, S., Greenberg, J., \& Pyszczynski, T. (1991). A terror management theory of social behavior: The psychological functions of self-esteem and cultural worldviews. In M. P. Zanna (Ed.), Advances in Experimental Social Psychology (Vol. 24, pp. 93-159). Academic Press. https://doi.org/10.1016/S0065-2601(08)60328-7

Steinman, C. T., \& Updegraff, J. A. (2015). Delay and death-thought accessibility: A metaanalysis. Personality and Social Psychology Bulletin, 41(12), 1682-1696. https://doi.org/10.1177/0146167215607843

Strachman, A., \& Schimel, J. (2006). Terror management and close relationships: Evidence that mortality salience reduces commitment among partners with different worldviews. Journal of Social and Personal Relationships, 23(6), 965-978. https://doi.org/10.1177/0265407506070477

Taubman Ben-Ari, O., Florian, V., \& Mikulincer, M. (1999). The impact of mortality salience on reckless driving: A test of terror management mechanisms. Journal of Personality and Social Psychology, 76(1), 35-45. http://dx.doi.org.elibrary.jcu.edu.au/10.1037/0022-3514.76.1.35

Penal Code, 298 Chapter 224135 (1871).

Sedition Act, Chapter 2901 (1948).

The Straits Times. (2020, January 31). Wuhan virus: WHO declares China virus outbreak an international emergency. The Straits Times. 
https://www.straitstimes.com/world/europe/wuhan-virus-who-declares-china-virusoutbreak-an-international-emergency

Wagenmakers, E.-J., Love, J., Marsman, M., Jamil, T., Ly, A., Verhagen, J., Selker, R., Gronau, Q. F., Dropmann, D., Boutin, B., Meerhoff, F., Knight, P., Raj, A., van Kesteren, E.-J., van Doorn, J., Šmíra, M., Epskamp, S., Etz, A., Matzke, D., ... Morey, R. D. (2018). Bayesian inference for psychology. Part II: Example applications with JASP. Psychonomic Bulletin \& Review, 25(1), 58-76. https://doi.org/10.3758/s13423-017-1323-7

Wagenmakers, E.-J., Marsman, M., Jamil, T., Ly, A., Verhagen, J., Love, J., Selker, R., Gronau, Q. F., Šmíra, M., Epskamp, S., Matzke, D., Rouder, J. N., \& Morey, R. D. (2018). Bayesian inference for psychology. Part I: Theoretical advantages and practical ramifications. Psychonomic Bulletin \& Review, 25(1), 35-57. https://doi.org/10.3758/s13423-017-1343-3

Watson, D., Clark, L. A., \& Tellegen, A. (1988). Development and validation of brief measures of positive and negative affect: The PANAS scales. Journal of Personality and Social Psychology, 54(6), 1063-1070.

Xu, H., \& Brucks, M. L. (2011). Are neurotics really more creative? Neuroticism's interaction with mortality salience in determining creative interest. Basic and Applied Social Psychology, 33(1), 88-99. https://doi.org/10.1080/01973533.2010.539962

Yen, C.-L., \& Cheng, C.-P. (2010). Terror management among Taiwanese: Worldview defence or resigning to fate? Asian Journal of Social Psychology, 13(3), 185-194. https://doi.org/10.1111/j.1467-839X.2010.01328.x

Yen, C.-L., \& Cheng, C.-P. (2013). Researcher effects on mortality salience research: A meta-analytic moderator analysis. Death Studies, 37(7), 636-652. https://doi.org/10.1080/07481187.2012.682290 
Zaleskiewicz, T., Gasiorowska, A., \& Kesebir, P. (2013). Saving can save from death anxiety: Mortality salience and financial decision-making. PLoS ONE, 8(11), e79407. https://doi.org/10.1371/journal.pone.0079407 


\section{Table 1}

Mean (Standard Deviation) Worldview Defense Assessment Scores for Offline and Online Participants in the Mortality Salience and Control Conditions

\begin{tabular}{|c|c|c|c|c|}
\hline \multirow[b]{2}{*}{ Variables } & \multicolumn{2}{|c|}{ Offline $(n=66)$} & \multicolumn{2}{|c|}{ Online $(n=80)$} \\
\hline & $\begin{array}{c}\mathrm{MS} \\
(n=33)\end{array}$ & $\begin{array}{l}\text { Control } \\
(n=33)\end{array}$ & $\begin{array}{c}\mathrm{MS} \\
(n=39)\end{array}$ & $\begin{array}{l}\text { Control } \\
(n=41)\end{array}$ \\
\hline Worldview Defense (Author) & $\begin{array}{l}3.12 \\
(3.60)\end{array}$ & $\begin{array}{c}2.51 \\
(5.15)\end{array}$ & $\begin{array}{l}2.49 \\
(3.71)\end{array}$ & $\begin{array}{c}3.29 \\
(5.60)\end{array}$ \\
\hline Worldview Defense (Content) & $\begin{array}{c}1.91 \\
(5.01)\end{array}$ & $\begin{array}{c}1.91 \\
(4.71)\end{array}$ & $\begin{array}{c}1.18 \\
(4.59)\end{array}$ & $\begin{array}{c}1.56 \\
(4.49)\end{array}$ \\
\hline
\end{tabular}

Note. Worldview Defense = evaluation scores of the pro-Singapore essay - evaluation scores of the anti-Singapore essay, with higher scores indicating higher levels of worldview defense; $\mathrm{MS}=$ mortality salience 